\title{
EVALUATION OF INTERNET OF THINGS UTILIZATION IN PRODUCT-SERVICE SYSTEM CASES
}

Renato Nunes Moraes (renato.moraes@usp.br) - Escola de Engenharia de São Carlos, Universidade de São Paulo (EESC/USP)

Marília Costa Rosendo Silva (marilia.costa.silva@usp.br) - Escola de Engenharia de São Carlos, Universidade de São Paulo (EESC/USP)

Maiara Rosa (maiara.rosa@usp.br) - Escola de Engenharia de São Carlos, Universidade de São Paulo (EESC/USP)

Henrique Rozenfeld (roz@usp.br) - Escola de Engenharia de São Carlos, Universidade de São Paulo (EESC/USP)

\begin{abstract}
PSS is an integrated offering of products and services that seek to satisfy stakeholders' needs. The relation product/service can vary in terms of functionality or economic value. Internet of Things (IoT) refers to the ability that objects have of interacting with each other and with the environment, making decisions and acting to achieve common goals. PSS offerings can profit from this technology. There are few studies that clarify the relationship between IoT and PSS. This work aims to evaluate current PSS cases that incorporate IoT concepts and elements, known as Smart Objects. The goal is to understand how those elements are used in the PSS context. The evaluation was performed based on 142 cases. An exploratory research verified which cases had IoT elements and their roles in the business process. This qualitative evaluation will serve as a basis to future systematization, aiming to classify and identify barriers and opportunities for IoT applications in PSS. From the 142 cases, only 16 had IoT components. Most of the cases came from the transportation area, more specifically car sharing services. This shows that IoT might not yet be seen as a potential resource to improve the value offer despite having many benefits.
\end{abstract}

Keywords: Internet of Things, IoT, PSS, Product-Service Systems, PSS

Area: Product Development Process Management

\section{INTRODUCTION}

Companies have been constantly trying to modify and improve the way that they offer value to their users and customers in order to survive the increasing market competition. ProductService Systems (PSS) appear as an alternative to enable this improvement as it proposes the transition from a pure product or service offering to a bundled product and service one. In this context, Internet of Things (IoT) is seen as an enabler of some PSS concepts, allowing the collection and sharing of information about products and Product-Service Systems (SEREGNI et al., 2016). The PSS offering can be extended in cases where the company is able to monitor and gather data about its product during the use lifecycle phase (ZANCUL et al., 2016).

There are many proposed definitions for PSS in literature, each one focusing on different aspects of it (e.g. (MANZINI; VEZZOLI, 2002; MEIER; VÖLKER; FUNKE, 2011; TUKKER, 2004; VASANTHA; ROY; CORNEY, 2015). Tukker's definition seems to be the most accepted definition (BAINES et al., 2007) and states that PSS are "tangible products and intangible services designed and combined so that they jointly are capable of fulfilling 
specific customer needs". However, it seems that a consensus on how to best categorize PSS was not achieved yet, making it worth exploring (BEUREN; GOMES FERREIRA; CAUCHICK MIGUEL, 2013).

Atzori, Iera and Morabito (2010) define IoT as a "novel paradigm that is rapidly gaining ground in the scenario of modern wireless telecommunications". It incorporates the concept of pervasive presence of things (e.g. Radio-Frequency Identification (RFID) tags, actuators, sensors, smartphones), which are uniquely addressable and able to communicate with each other in order to achieve common goals.

The use of IoT solutions in PSS offerings may be a new possibility to integrate different functionalities and to provide better offerings. Rapid technological developments have created possibilities for innovative production systems, enabling new processes and methods, and reducing "time to market", waste and failures (CHANG; YAN; CHEN, 2013; LEE et al., 2010).

This paper provides an analytic study and understanding of PSS cases that have incorporated IoT in their offering. In detail, this work classifies the cases according to the areas presented by Porter and Heppelmann (2014), which will be discussed later. The selected cases are resultant from a theoretical systematization, which was previously conducted in the research group. Finally, the aim of this paper is to clarify the relationship between PSS and IoT-based business cases, seeking to identify mutual benefits between them and the impacts of this combination on the value offering.

The present work is organized as follows: section 2 shows the literature review, presenting the current understanding of PSS and IoT as well as their relationship. Section 3 presents the research methodology about how the cases were gathered and classified. Section 4 describes the most important cases and compares them in the IoT and industry field level. Finally, section 5 presents comments about the obtained results.

\section{LITERATURE REVIEW}

The PSS concept rests on two pillars (TUKKER; TISCHNER, 2006):

- Considering the final functionality, result or satisfaction that the user needs or desires as the primary point to the business development.

- Elaborating the business system in a greenfield environment and not taking existing structures.

According to Tukker (2004), many people consider PSS as a way to improve competitiveness. In many markets, products have become equally well performing commodities. A PSS business model allows companies to identify innovative ways of adding value and competitiveness by means of:

- fulfilling users' needs in an integrated and customized way;

- narrowing the relationship between customers and provider, creating a loyal relation;

- creating the possibility to innovate faster, since the customer needs are listened to.

IoT allows collaboration among many levels, promoting interaction among people, among things and among people and things, which is the basis for information collaboration (LEE; LEE, 2015). According to Rymazewska, Helo and Gunasekaran (2015) "value creation can be much more effective if real-time information is flowing seamlessly on the three 
aforementioned levels - and when it is shared between collaborating entities (people and things)".

Espíndola et al. (2012) say that the adoption of the PSS paradigm of "(re)adding value, (re)use and customization, based on the different expectations from distinct agents, require new technologies for its implementation. New Information and Communication Technologies (ICT) infrastructures for acquiring and processing of information, such as smart devices, human-computer interfaces and computational models are required."

To enable a combination of pervasive computing and the necessity of embedding ICT on all devices of PSS, Internet of Things (IoT) has emerged as a possible and potential solution. The IoT is a novel paradigm that makes possible the pervasive presence around us of a variety of things or objects (ESPÍNDOLA et al., 2012).

Kortuem et al. (2010) introduce a definition for smart objects: autonomous physical/digital objects augmented with sensing, processing, and network capabilities.

According to Porter e Heppelmann (2014), the intelligence and connectivity of smart objects - or "smart, connected products", as used by them - can enable an entirely new set of functions and capabilities. That allows the smart objects to be grouped in four capabilities: monitoring, control, optimizing and autonomy, as shown in Figure 1.

The monitoring capability enables the comprehensive monitoring of a smart object condition, operation, and external environment through sensors and external data sources. The control capability allows remote commands or algorithms that are built into the device or reside in the product cloud to control the smart object. Optimizing is the possibility of applying algorithms and analytics to in-use or historical data for to dramatically improve output, utilization, and efficiency. Finally, autonomy is when human operators merely monitor performance or watch over the fleet or the system, rather than over individual units (PORTER; HEPPELMANN, 2014).

Figure 1 - Capabilities of Smart, Connected Products. Source: Porter and Heppelmann (2014, p. 8)

\section{CAPABILITIES OF SMART, CONNECTED PRODUCTS}

The capabilities of smart, connected products can be grouped into four areas: monitoring, control, optimization, and autonomy. Each builds on the preceding one; to have control capability, for example, a product must have monitoring capability.
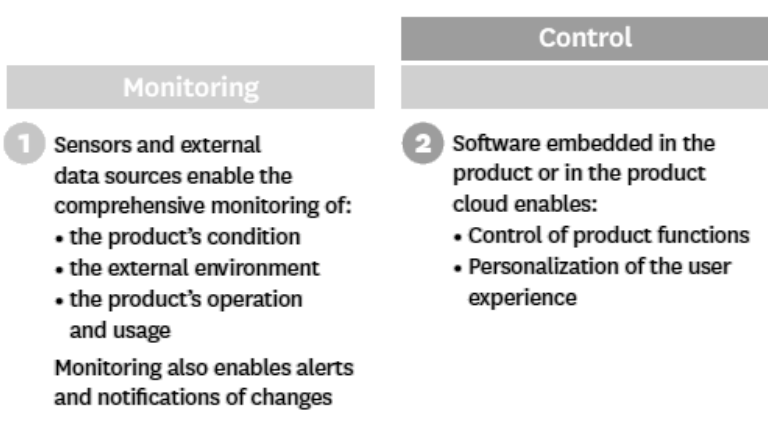

Optimization

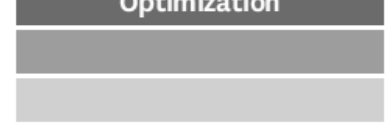

Monitoring and control capabilities enable algorithms that optimize product operation and use in order to: - Enhance product performance - Allow predictive diagnostics, service, and repair

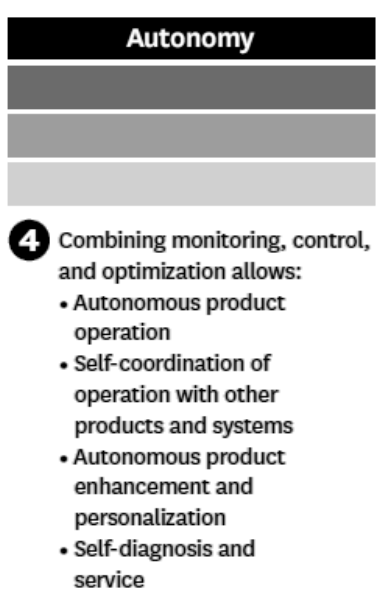

RFID (Radio-Frequency IDentification) was one of the most relevant technologies that enabled the implementation of wireless and smart solutions. It consists in an identification method that can also track tags attached to objects, acting as an electronic barcode 
(WELBOURNE et al., 2009). The tags contain electronically stored information and interact with a RFID reader through radio waves.

RFID transmits raw data. It can be understood as a previous and less mature version of smart objects due to its lack of embedded data processing. The challenge of how to use the potential of RFID on IoT solutions has been widely discussed (WELBOURNE et al., 2009), but this technology is acknowledged for its importance and for being an inspiration to the IoT tendency (ATZORI; IERA; MORABITO, 2010; GUBBI et al., 2013; KORTUEM et al., 2010).

\section{RESEARCH METHODOLOGY}

The first step in the methodology was to build a database of PSS cases. The cases sample was not big enough to conduct a quantitative analysis. For this reason, the PSS cases in this work were analyzed by a qualitative methodological approach.

PSS offering cases with IoT components were identified by means of an analysis of the cases that were contained in the database. A content analysis was conducted to define proper categories of the IoT cases. The smart objects categories were defined by Porter and Heppelmann (2014) and those categories were presented in the previous section.

As a complement to this categorization, this work also considered the RFID (RadioFrequency IDentification) category. RFID tags are not considered smart objects (KORTUEM et al., 2010). However, RFID is put as a category of IoT solution, since it is mainly used for identification. It can be considered as a previous stage of the monitoring level. Therefore, 5 categories were used to classify the PSS cases: RFID, Monitoring, Control, Optimizing and Autonomy.

The lack of standardization on how each document describes its case is the biggest difficulty in the process of finding PSS cases. To solve this problem and facilitate the access to them, a database was created in order to enable the easy addition of new cases found in the literature and websites.

Data collecting was the first activity in the cases database building process. It began with online research in websites such as "MePSS" (2006) and academic papers (MONT, 2002; MONT; DALHAMMAR; JACOBSSON, 2006; REIM; PARIDA; ÖRTQVIST, 2015). The snowballing technique was used to identify other publications that presented cases in their content. The most common keywords were extracted from those publications, what led to a search string that was employed in the Scopus database (ELSEVIER, 2016) as a primary source of academic PSS cases.

A group of 142 PSS cases yielded from the literature review on Scopus database and searches on websites through snowballing. To classify them, the categories were defined according to Bardin's (2011) content analysis method.

The cases with IoT components were selected through an exploratory qualitative research and their basic information was collected in a worksheet. To analyze real cases in a proper way, it was necessary to conduct a web search and look for technical aspects of the solution. Most of the details could be found in the company's website or in academic articles. The cases without enough data were not considered in this study. 


\section{PSS AND IOT CASES ANALYSIS}

From the 142 cases yielded from the exploration phase, only 16 had IoT components. Those cases and their details are presented in the next paragraphs.

I-pot - An electric kettle, an "i-pot" (information pot), boils the water and can record the time of operation. During the use, a wireless communication system sends a signal to a server, allowing the customer or the staff to access its data through a website. (ABEELE, 2014).

Be park - Uses the concept of "parksharing", in which places like hotels, supermarkets and underused car parking lots make their space available to drivers. Thanks to the automated parking management system, the customer is able, with the help of his telephone, to locate, access, book and pay for the parking (ABEELE, 2014).

Car2Go, Zazcar - Car sharing solution, the customer can pick any available car on the street, drive it to wherever he wants to go and drop it in any place inside an operating area. Everything is done by means of an app, where the user can see the available cars in GPS and unlock them via smartphone. (CAR2GO, 2017; ZAZCAR, 2017).

Enterprise Car Share, Cambio, Greenwheels, Zipcar, GoGet - A car sharing solution that uses RFID technology to identify users and unlock the cars (CAMBIO, 2017; ENTERPRISE, 2017; GOGET, 2017; GREENWHEELS, 2017; ZIPCAR, 2017).

PFI Lightning System - The project is based on an agreement among Hampshire County Council, United Kingdom, and SSI Contracting. The contractor has the responsibility for establishing and maintaining a lighting network for a contractually determined sum. They have monitoring technologies to control lights and a centrally controlled system to detect faults (SSE ENTERPRISE, 2008).

TC Energy - An integrated solution for energy management and building management. TC Energy, within the Top-Control Suite, provides an online and clear overview of the most relevant energy information. It gathers all the energy data and transforms it into information that anyone can understand (ABEELE, 2014).

Philips pay-per-lux - Business customers pay a regular fee for Philips to handle their entire lighting service - design, equipment, installation, maintenance and upgrades - only paying for each unit of light that was consumed - the 'lux'. The long-term plan aims to make itavailable for everyone. The Philips Smart meters record the energy consumption and indicate how and where this energy has been used (ABEELE, 2014).

Case study from Benedetti et al. (2016) - Energy consumption monitoring and control software. The energy meters are connected to the internet, and measured data are automatically read, elaborated and saved on a cloud. Then, they are ready to be analyzed by a software.

Three cases were described by Rymaszewska, Helo and Gunasekaran (2015):

- Company A - Provider of machinery for metal sheet processing. The developed IoT solution provides an opportunity to monitor actual production and daily key performance indicators;

- Company B - Provider of power generators. IoT systems help scheduling maintenance based on the product performance. A condition-based maintenance (CBM) system collects data from the machinery and compares them to control limits.

- Company C - Provider of technology for power generation and distribution. A sensor in the equipment monitors its operation in order to keep track of the conditions, seeking to extend its lifecycle through maintenance. 
As shown in Error! Reference source not found., 5 cases were classified in the RFID category, 4 cases in the Monitoring category, 4 cases in the Control category and 1 case in the Optimizing category. No cases were classified in the Autonomy category. Figure 2 shows those cases divided by business segment.

The number of cases with IoT components compared to those ones without them is significantly lower (around 11\%). This may indicate that IoT solutions are not seen yet as a potential complement to PSS offerings. It is also possible to consider that a cultural shift may be necessary for bringing this technological benefit as part of the value offering.

Most of the IoT cases are in the transportation area, all of them in the car sharing segment. Furthermore, most cases in this segment are in the RFID category, showing that the maturity of the IoT solution is very low. The Car2Go and Zazcar, for example, are in the Control category, showing that it is, indeed, possible to improve the quality of the IoT solution in this segment.

The cases brought by Rymaszewska, Helo and Gunasekaran (2015) explicitly indicate the idea of improving the value offer of the PSS: "due to the spread of the IoT, the case companies have redesigned their service propositions based on creating value to their customers by offering services that are best suited to the actual customer needs considering how the products are actually used."

According to the previously defined categories, it is noticeable that IoT are insufficiently incorporated by most cases. No cases were found in the autonomy category. This may suggest that PSS offerings do not demand the incorporation of a high-level smart objects intelligence.

Table 1 - Cases separated by category

\begin{tabular}{|c|c|}
\hline Case & Category \\
\hline Enterprise Car Share & \multirow{5}{*}{ RFID } \\
\hline Cambio & \\
\hline Greenwheels & \\
\hline Zipcar & \\
\hline GoGet & \\
\hline I-pot & \multirow{4}{*}{ Monitoring } \\
\hline Be Park & \\
\hline PFI Lightning System & \\
\hline TC Energy & \\
\hline $\begin{array}{c}\text { Company A, B and C from } \\
\text { Rymaszewska, Helo and } \\
\text { Gunasekaran (2015) }\end{array}$ & \multirow{4}{*}{ Control } \\
\hline Car2Go & \\
\hline Zazcar & \\
\hline $\begin{array}{l}\text { Case study from Benedetti et al. } \\
\text { (2016) }\end{array}$ & \\
\hline Philips pay-per-lux & Optimizing \\
\hline
\end{tabular}


Figure 2 - Cases per application area

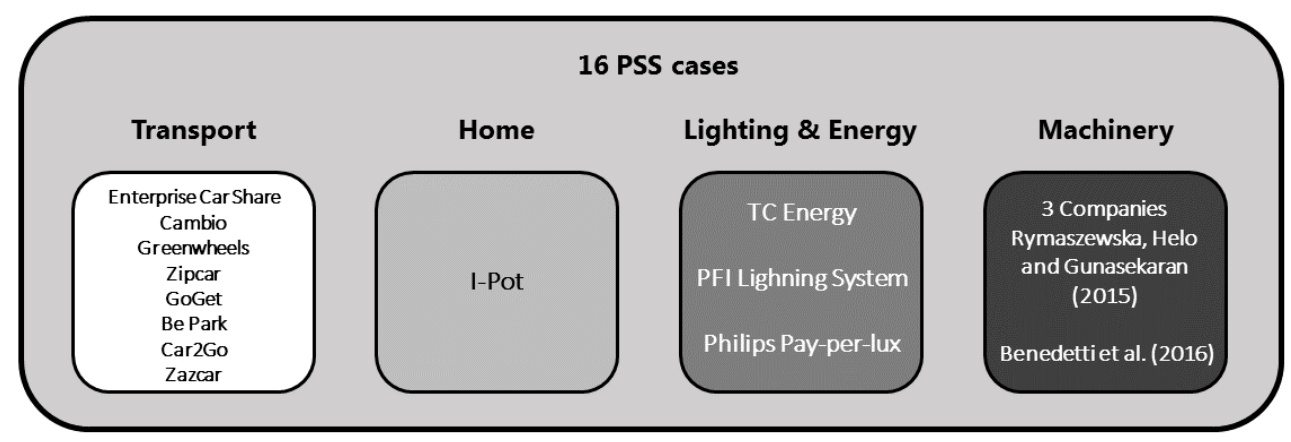

Most of the cases cite IoT as a means of acquiring data to be used in the service offering improvement. None of them explores the smart objects' capability of making decisions or acting by itself over an environment. This could be an opportunity for PSS providers to explore the market where the PSS itself is designed as an IoT proposition, and not taking IoT as a simple complement to the offering. With this, IoT could be used with higher capabilities, such as autonomy.

\section{COMMENTS}

This work presented a PSS case database building process as well as the analysis of those cases from an IoT solution perspective. The cases were classified regarding their level of IoT capability and their business segment. New different cases appear every day and that is why it is important to keep track of those cases to make it easier to draw a line between the academia and the business world.

It seems that the future of the association ofIoT and PSS is still blurry. Besides the literature raising its potential for improving the PSS offering, the cases show that this relation is still somehow immature and needs to be thoroughly studied in order to achieve a better understanding of it. Many authors talk about the benefits of employing IoT on PSS solutions, but the lack of case studies suggests that this value is not yet completely stated and needs to be clarified in order to maximize the use of those technologies.

The cases database construction is useful to bring a primary overview of the situation of PSS implementation. Further researches in this area could use this data to systematize the ideation, development and implementation of PSS solutions with IoT elements. Also, this work identified some gaps that could be explored: how to shift the mindset of PSS providers to incorporate smart objects in their solution? Which level - if there is a level - of smart objects could be considered as "ideal" for a PSS offering? Finally, how maximizing the use of smart objects in PSS offerings could improve the general PSS provision?

Some limitations of this work: it was not possible to conduct a quantitative study due to the small amount of case samples found. In addition, some case sources did not provide enough data to evaluate if the solution had smart objects or IoT elements.

Many of the cases were found on academic publications. This shows that the habit of trying and registering new solutions should also be encouraged outside academia, since it is a good environment to experiment. 


\section{ACKNOWLEDGEMENTS}

This work was supported by the São Paulo Research Foundation (FAPESP), process number 2015/23094-6. In addition, the authors thank the support from the National Council for Scientific and Technological Development (CNPq) and the Coordination for the Improvement of Higher Education Personnel (CAPES).

\section{REFERENCES}

ABEELE, P. VAN DEN. Summary of the cases of Product Service System. Transitioning towards Urban Resilience and Sustainability TURAS, p. 94, 2014.

ATZORI, L.; IERA, A.; MORABITO, G. The Internet of Things: A survey. Computer Networks, v. 54, n. 15, p. 2787-2805, 2010.

BAINES, T. S. et al. State-of-the-art in product-service systems. Proceedings of the Institution of Mechanical Engineers, Part B: Journal of Engineering Manufacture, v. 221, n. 10, p. 1543-1552, 2007.

BARDIN, L. Análise de conteúdo. 1. ed. São Paulo: Edições 70, 2011.

BENEDETTI, M. et al. Service Engineering Methodology and Energy Services: Applicability Analysis and Case Study. Procedia CIRP, v. 47, p. 358-363, 2016.

BEUREN, F. H.; GOMES FERREIRA, M. G.; CAUCHICK MIGUEL, P. A. Product-service systems: A literature review on integrated products and services. Journal of Cleaner Production, v. 47, p. 222-231, 2013.

CAMBIO. Cambio Carsharing. Disponível em: <http://www.cambio-carsharing.de>. Acesso em: 5 jun. 2017.

CAR2GO. Car2Go Carsharing. Disponível em: <www.car2go.com>. Acesso em: 5 jun. 2017.

CHANG, W.; YAN, W.; CHEN, C.-H. Customer Requirements Elicitation and Management for Product Conceptualization. In: Concurrent Engineering Approaches for Sustainable Product Development in a Multi-Disciplinary Environment SE - 81. [s.1.] Springer, 2013. p. 957-968.

ELSEVIER. Scopus. Disponível em: <https://www.scopus.com/>.

ENTERPRISE. Enterprise Car Share. Disponível em: 〈https://www.enterprisecarshare.ca>. Acesso em: 5 jun. 2017.

ESPÍNDOLA, D. et al. Internet of Things to Provide Scalability in Product-Service Systems Center for Computational Science Federal University of Rio Grande School of Electrical Engineering Federal University of Rio Grande do Sul. n. c, p. 214-221, 2012.

GOGET. GoGet Car Sharing. Disponível em: <https://www.goget.com.au/>.

GREENWHEELS. Greenwheels Car Sharing. Disponível em: <https://www.greenwheels.com>. Acesso em: 5 jun. 2017.

GUBBI, J. et al. Internet of Things (IoT): A vision, architectural elements, and future directions. Future Generation Computer Systems, v. 29, n. 7, p. 1645-1660, 2013.

KORTUEM, G. et al. Smart objects as building blocks for the Internet of things. Internet Computing, IEEE, v. 14, n. 1, p. 44-51, 2010.

LEE, I.; LEE, K. The Internet of Things (IoT): Applications, investments, and challenges for 
enterprises. Business Horizons, v. 58, n. 4, p. 431-440, 2015.

LEE, S. et al. Open innovation in SMEs - An intermediated network model. Research Policy, v. 39, n. 2, p. 290-300, 2010.

MANZINI, E.; VEZZOLI, C. Product-Service Systems and Sustainability: Opportunities for sustainable solutions. Paris: [s.n.].

MEIER, H.; VÖLKER, O.; FUNKE, B. Industrial Product-Service Systems (IPS2) : Paradigm shift by mutually determined products and services. International Journal of Advanced Manufacturing Technology, v. 52, n. 9-12, p. 1175-1191, 2011.

MePSS. Disponível em: <http://mepss.nl>. Acesso em: 26 maio. 2017.

MONT, O. Clarifying the concept of product-service system. Journal of Cleaner Production, v. 10, n. 3, p. 237-245, jun. 2002.

MONT, O.; DALHAMMAR, C.; JACOBSSON, N. A new business model for baby prams based on leasing and product remanufacturing. Journal of Cleaner Production, v. 14, n. 17, p. 1509-1518, 2006.

PORTER, M. E.; HEPPELMANN, J. E. How Smart, Connected Products Are Transforming Competition. Harvard Business Review, n. November, p. 1-23, 2014.

REIM, W.; PARIDA, V.; ÖRTQVIST, D. Product-Service Systems (PSS) business models and tactics - A systematic literature review. Journal of Cleaner Production, v. 97, p. 61-75, 2015.

RYMASZEWSKA, A.; HELO, P.; GUNASEKARAN, A. IoT powered servitization of manufacturing - an exploratory case study. International Journal of Production Economics, $\mathrm{n}$. October 2015, p. 1-14, 2015.

SEREGNI, M. et al. The impact of IoT Technologies on product-oriented PSS. The "Home Delivery" service case. Rtsi 2016, 2016.

SSE ENTERPRISE. Improving Your Street Lightning. 2008.

TUKKER, A. Eight types of product-service system: Eight ways to sustainability? Experiences from suspronet. Business Strategy and the Environment, v. 13, n. 4, p. 246-260, 2004.

TUKKER, A.; TISCHNER, U. Product-services as a research field: past, present and future. Reflections from a decade of research. Journal of Cleaner Production, v. 14, n. 17, p. 15521556, 2006.

VASANTHA, G. V. A.; ROY, R.; CORNEY, J. R. Advances in Designing Product-Service SystemsJournal of the Indian Institute of Science, 2015.

WELBOURNE, E. et al. Building the Internet of Things Using RFID. Internet Computing, IEEE, v. 13, n. 3, p. 48-55, 2009.

ZANCUL, E. DE S. et al. Business process support for IoT based product-service systems (PSS). Business Process Management Journal, v. 22, n. 2, p. 305-323, 2016.

ZAZCAR. Zazcar - Carro on Demand. Disponível em: <http://www.zazcar.com.br/>. Acesso em: 5 jun. 2017.

ZIPCAR. Zipcar. Disponível em: <http://www.zipcar.com>. 